\title{
Desain Komunikasi Visual Feed Instagram Sebagai Penunjang Informasi Dan Promosi Pada PT. Timoti Beauty Indonesia
}

\author{
Wahyu Hidayat $^{* 1}$, Ghina Cendikia Madani ${ }^{2}$, Upi Indria ${ }^{3}$ \\ ${ }^{1,2,3}$ Program Studi Teknik Informatika Fakultas Sains dan Teknologi Universitas Raharja \\ E-mail: *11 wahyu.hidayat@ raharja.info, ${ }^{2}$ ghina.cendikia@ raharja.info, \\ upi.indria@raharja.info
}

\begin{abstract}
Abstrak
PT. Timoti Beauty Indonesia adalah perusahaan yang bergerak di bidang distribusi produk kecantikan, bertujuan untuk memberikan perawatan kulit yang terbaik, sehat dan efektif. Saat ini PT. Timoti Beauty Indonesia membutuhkan media desain sebagai solusi pemecahan masalah dalam rencana promosi. Menyadari kemajuan teknologi salah satunya adalah media sosial yaitu Instagram yang telah banyak digunakan oleh anak muda saat ini. Alasan memilih Instagram sebab sedang menjadi trend baru tidak hanya Faceboook serta Twitter. Instagram juga menempati urutan ketiga di antara sebagian besar pengguna aplikasi di dunia. Tujuan dibuatnya desain feed yaitu untuk membantu PT. Timoti Beauty Indonesia dalam menginformasikan serta mempromosikan produk skincare kepada calon konsumen dan meningkatkan penjualan produk yang di dukung konsep desain, gambar, foto maupun ilustrasi yang dimana nantinya Instagram feed yang sejalan dengan trend saat ini dapat menarik perhatian dari calon konsumen. Metode dalam penelitian ini yakni: analisa kasus, pengumpulan informasi, analisa perancangan media serta konsep desain. Desain feed Instagram yang nantinya akan menampilkan feed desain untuk menginformasikan waktu saat live streaming pada instagram dan juga menginformasikan adanya spesial harga pada marketplace. Melalui feed Instagram tersebut, konsumen akan semakin tertarik mengunjungi Instagram dan membeli produk dari Timoti Beauty.
\end{abstract}

Kata Kunci — Instagram, Media Komunikasi Visual, Desain promo

\begin{abstract}
PT. Timoti Beauty Indonesia is a company engaged in the distribution of beauty products, aiming to provide the best skin care, healthy and effective. Currently PT. Timoti Beauty Indonesia needs a design media as a solution to the problem in the promotional plan. Realizing the advancement of technology today one of them is social media that is Instagram that has been widely used by young people today. The reason for choosing Instagram is because it is becoming a new trend not only Faceboook and Twitter. Instagram also ranks third among most app users in the world. The purpose of the feed design is to help PT. Timoti Beauty Indonesia in informing and promoting skincare products supported by design concepts, drawings, photos and illustrations to prospective consumers and increasing sales of products where later Instagram feeds that are in line with the current trend can attract the attention of prospective consumers. The research methods are: problem analysis, data collection, media design analysis and design concept. Instagram feed design that will later display a design feed to inform the time when live streaming on instagram and also inform the existence of special prices on the marketplace. Through the Instagram feed, consumers will be more interested in visiting Instagram and buying products from Timoti Beauty.
\end{abstract}

Keywords — Instagram, visual communication media, promo design 


\section{PENDAHULUAN}

Dalam dunia pemasaran, periklanan dan promosi merupakan hal yang harus dipahami. Karena pemasaran adalah upaya memasarkan produk (termasuk barang dan jasa). Oleh karena itu, melalui periklanan dan promosi, tujuan ini akan tercapai. Periklanan adalah pekerjaan yang dilakukan untuk mempengaruhi mentalitas konsumen dalam membeli produk yang disediakan secara tidak langsung. Promosi sering juga disebut dengan penyediaan barang / jasa kepada konsumen yang tujuannya untuk menarik calon konsumen dan langsung membeli produk yang disediakan ${ }^{[1]}$. Perusahaan harus mengembangkan strategi pemasaran, termasuk periklanan dan promosi. Hal paling sederhana yang bisa dilakukan adalah memiliki akun bisnis, namun harus sesuai dengan situasi saat ini ${ }^{[2]}$.

Promosi merupakan aksi menginformasikan ataupun menegaskan tentang spesifikasi produk ataupun merk. Aktivitas promosi yang dicoba berperan untuk menyebar luaskan data serta memperoleh atensi (attention), menghasilkan serta meningkatkan kemauan (desire), dan meningkatkan kemauan konsumen untuk membeli produk yanag ditawarkan ${ }^{[3]}$. Beberapa strategi promosi berupaya membangun permintaan primer. Sebaliknya sebagian besar strategi promosi berupaya memicu permintaan selektif ialah kemauan untuk memperoleh sesuatu merk tertentu.

Tujuan promosi menyebabkan kemauan para calon konsumen untuk membeli produk ataupun jasa yang dihasilkan serta pula keingingan para calon wisatawan buat berkunjung ke wisata yang dituju. Oleh karena itu wajib di upayakan bagimana mempengaruhi pola fikir calon konsumen ataupun wisatawan agar yakin. Sebaliknya kata promosi wajib baik serta menarik. Sehingga memberikan kesan jika calon konsumen ataupun wisatawan tidak menghendaki produk ataupun wisata yang lain ${ }^{[4]}$.

Media merupakan alat atau sarana yang digunakan untuk menyampaikan informasi kepada masyarakat. Sebagian psikolog yakin bahwa dalam komunikasi antar manusia, media terutama dalam komunikasi yakni panca indera, seperti mata dan telinga. Pesan yang berikutnya diterima oleh indera setelah itu diproses oleh otak manusia untuk mengendalikan serta menghentikan perilakunya terhadap hal-hal tertentu, dan kemudian mengekspresikannya sebagai tindakan ${ }^{[5]}$. Media sosial adalah media baru yang paling banyak digunakan. Pada dasarnya media sosial adalah media yang digunakan untuk komunikasi online atau jaringan. Hal ini membuat proses komunikasi menjadi lebih mudah bagi banyak orang karena sangat fleksibel dalam hal efisiensi ruang dan waktu ${ }^{[6]}$.

Dengan bertambahnya jumlah pengguna, perkembangan media sosial semakin luas dan besar. Sosmed atau dikenal sebagai media sosial yang selalu kita jumpai dikehidupan seharihari adalah Facebook, Twitter, Instagram, Snapchat, Youtube dan masih banyak aplikasi media sosial baru lainnya ${ }^{[7]}$. Fungsi yang diberikan antara satu media sosial dengan media sosial lainnya hampir sama. Seiring dengan berkembangnya media sosial, media sosial sering digunakan dengan berbagai cara, misalnya dalam dunia bisnis. Pelaku bisnis memanfaatkan peluang yang disediakan oleh media sosial untuk iklan dan promosi. Hal ini niscaya akan membuat bisnis yang sedang beroperasi semakin dikenal luas, dan dengan banyaknya orang yang mengenal usaha tersebut, maka peluang besar untuk mendapatkan lebih banyak konsumen ${ }^{[8]}$. Sehingga dalam menjawab fenomena media sosial tersebut, maka perlu adanya pengembangan media sosial melaksanakan kegiatan promosi di sebuah perusahaan.

Dalam mengembangkan bisnisnya, PT. Timoti Beauty Indonesia sangat dibutuhkannya sarana promosi dan informasi dalam bentuk yang menarik melalui visualisasi (dalam bentuk feed di media sosial Instagram). Diharapkan dapat menarik calon konsumen, menjalin hubungan baik atau kerjasama dengan nasabah perorangan, instansi atau instansi terkait dan sebagai media informasi untuk meningkatkan citra image PT. Timoti Beauty Indonesia agar lebih dikenal khususnya Tangerang dan sekitarnya. Dengan menggunakan media promosi berupa Instagram feed maka PT. Timoti Beauty Indonesia akan semakin menarik dalam menyampaikan informasi serta dapat mempromosikan produk yg ditawarkannya. 


\section{METODE PENELITIAN}

Dalam Penyusunan penelitian saat ini, memakai sebagian metode yang akan diimplementasikan, diantara lain: (1) Metode pengumpulan data melalui: (a) Observasi (Observation Research), observasi adalah pengambilan informasi melalui wawancara yang dilaksanakan langsung dengan dengan melakukan magang di PT. Timoti Beauty Indonesia pada bagian design grafis. (b) Wawancara ( Interview), Wawancara dilakukan secara metodis, yaitu melalui wawancara dengan PT. Timoti Beauty Indonesia. Wawancara ini dengan stakeholder Lian Anggraeni sebagai direktur bertempat di PT. Timoti Beauty Indonesia. (c) Studi Pustaka, selain melakukan interview dan observasi penulis juga menyeleksi lengkap data yang relevan dalam judul yang dikirimkan, baik dari jurnal, buku-buku, proceeddings atau dari referensi terkait dengan pembahasan penulisan. (2) Metode analisa perancangan media Desain Komunikasi Visual Feed Instagram sebagai penunjang informasi dan promosi pada PT. Timoti Beauty Indonesia menggunakan 2 software penunjang desain yaitu menggunakan Adobe Photoshop CC dan Corel Draw X7. Konsep desain ini menggunakan layout kasar, komprehensif dan final artwork.

\section{Literature Review}

Berikut adalah literature review yang terkait dengan topik penelitian:

Riset yang dilakukan oleh Maimunah, dkk Paper Semnasteknomedia Vol 3, Nomor 1 $(2015)^{[9]}$, yang bertajuk "Enriching Merchandise sebagai Salah Satu Media Promosi Mall Taman Palem". Untuk menarik perhatian kepada calon-calon konsumen atau masyarakat luas beserta mitranya, Mall Taman Palem memerlukan media promosi salah satunya merchandise (cendramata). Secara umum, fungsi suatu komoditas merupakan sebagai fasilitas pendukung untuk aktivitas promosi perusahaan lembaga ataupun agen tertentu tersebut juga digunakan sebagai strategi pemasaran. Produk-produk tersebut diharapkan dapat membentuk citra perusahaan yang positif di masyarakat luas. Saat ini jenis barang yang ada di mall Taman Palem masih sangat sedikit, serta terdapat kesatuan antara satu proyek desain dengan proyek desain lain, sehingga dapat menampilkan citra ataupun citra perusahaan, dan setiap bentuk desain yang hendak dibuat, desain produk media yang akan diproduksi meliputi desain gelas (cup), desain karton untuk parsel, desain folder surat, desain payung serta desain topi.

Penelitian atau riset yang dilakukan oleh Lusyani Sunarya, beserta teman-temannya, pada Journal CCIT Vol. 9 Nomor. 1 pada tahun 2015 ${ }^{[10]}$, Kajian yang bertajuk "Keefektifan Media Komunikasi Visual Sebagai Penunjang Promosi Pada Perguruan Tinggi Raharja" menerangkan bahwa media komunikasi visual sangat penting serta dapat digunakan di perguruan tinggi Raharja untuk memperkenalkan atau meningkatkan popularitas dan citra image, serta pula untuk memberikan dan mempromosikan informasi kepada calon mahasiswa dan mahasiswa baru. Mengevaluasi keefektifan media publisitas dalam menyebarkan informasi, mempengaruhi ataupun membujuk calon mahasiswa dan mahasiswa baru untuk mendaftar.

Riset yang dilakukan oleh Riska Andriyanti pada tahun (2016) ${ }^{[11]}$. Penelitian yang bertajuk "Perancangan Majalah Sebagai Penunjang Informasi Dan Promosi Pada TK Putra IX Tangerang". Penelitian ini membahas tentang promosi dan informasi sekolah serta informasi lainnya yang bertujuan untuk meningkatkan siswa dan calon siswa baru pada TK Putra IX Tangerang. Tujuan pembuatan media promosi berupa majalah adalah agar dapat meningkatkan citra dan image dibuatnya desain majalah dengan kreatif dan menarik agar dapat meningkatkan siswa baru disetiap tahunnya bagi TK Putra IX Tangerang

Riset yang dilakukan oleh Lusyani Sunarya dan teman-temannya pada Journal SISITI Volume 5, Nomor 1 pada tahun 2017 ${ }^{[12]}$, yang bertajuk "Desain Komunikasi Visual Sebagai Media Promosi Pada SMK Al-Hikmah Curug Kabupaten Tangerang”. Kegiatan promosi pada sekolah SMK Al-Hikmah menggunakan media desain komunikasi visual. Tujuannya agar sekolah dapat mencapai target sasaran pemasarannya setiap tahun dan dapat meningkatkan citra sekolah sehingga masyarakat luas dapat lebih memahaminya. Berdasarkan analisis masalah 
pada sekolah SMK Al-Hikmah Curug Kab. Tangerang harus terus bekerja keras menerapkan strategi pemasaran yang efektif agar sukses dan menjaring calon mahasiswa baru. Untuk menunjang kegiatan promosinya, sekolah membutuhkan media komunikasi visual yang diyakini efektif dalam memberikan informasi dan promosi. Diharapkan melalui perancangan desain media komunikasi visual, informasi tentang sekolah SMK Al-Hikmah dapat diperluas, dan citra image SMK Al-Hikmah Curug dapat ditingkatkan, sehingga dapat dipahami oleh masyarakat atau komunitas yang lebih luas.

Penelitian yang dilakukan oleh Aris pada tahun $2017^{[13]}$, Judul penelitiannya adalah "Pengaruh Promosi Melalui Media Sosial Instagram Terhadap Keputusan Pembelian Produk Saka Bistro \& Bar". Studi tersebut menjelaskan bahwa Bandung saat ini terkenal dengan kota kulinernya, dan terdapat tempat makan hampir di setiap sudut kota, mulai dari warung pinggir jalan hingga berbagai jenis restoran, kafe dan jenis tempat lainnya. Banyaknya restoran dan kafe serupa memaksa Saka Bistro berinovasi dalam memasarkan makanannya. Semakin banyak pengguna media sosial Instagram yang dimanfaatkan oleh Saka Bistro \& Bar sebagai media terpopuler diandalkan karena tidak memiliki batasan jumlah karakter yang ditulis, dapat memuat foto, bersifat global, dan pada dasarnya seperti majalah berjalan. Tujuan dari riset ini merupakan untuk mengenali seberapa besar pengaruh pemakaian media sosial lewat Instagram untuk aktivitas promosi terhadap keputusan pembelian konsumen atas produk Saka Bistro \& Bar. Jenis penelitian ini adalah penelitian deskriptif. Analisis informasi yang digunakan merupakan regresi linier simpel, serta hasil riset menampilkan dalam hal pemakaian promosi melalui media sosial Instagram mempengaruhi $83 \%$ terhadap keputusan pembelian konsumen untuk produk Saka Bistro \& Bar dan sebaliknya sisanya dipengaruhi oleh faktor- faktor lain.

\section{HASIL DAN PEMBAHASAN}

\subsection{Konsep Perancangan}

Perancangan media desain komunikasi visual feed Instagram sebagai penunjang informasi dan promosi pada PT. Timoti Beauty Indonesia ini memiliki beberapa konsep perancangan, yaitu:

\section{Perencanaan Media}

Mengenai hal ini konsep media yang disarankan adalah perancangan media promosi dan informasi dalam bentuk desain feed Instagram dengan ukuran 1:1. Semua konten yang terkait dengan desain feed Instagram yang direncanakan dikembangkan dan dikemas menggunakan desain grafis yang kreatif.

2. Strategi Media

Untuk mendukung nilai efektivitas media, telah dirancang strategi media informasi, penggunaan komunikasi visual berupa media desain, menggunakan teknologi gambar yang dihasilkan oleh aplikasi untuk menunjukkan arah gambar mendukung berupa gambar vector.

3. Perencanaan Pesan (Konsep Kreatif)

Desain media yg direncanakan menampilkan beberapa konten bersifat modern yaitu gaya desain yang unik dan menarik yang mengedepankan eksplorasi warna-warna lembut, Serta diperjelas dengan font yang sesuai dengan tema desain. Tampilan desain kreatif akan ditangani sesuai dengan kebutuhan pada PT. Timoti Beauty Indonesia.

4. Perencanaan Visual

Penyajian desain feed Instagram dengan tetap mempertahankan warna pastel yang diolah dengan kombinasi bentuk tulisan yang dibutuhkan oleh perusahaan. Dan menggunakan gambar produk sesuai dengan instruksi perusahaan dan diproses oleh berbagai perangkat lunak pendukung yaitu Corel Draw dan Adobe Photoshop. Melalui penggunaan konsep desain, ilustrasi, gambar dan foto, serta pedoman pengemasan, menjadi salah satu daya tarik para calon costumer.

\subsection{Tujuan Desain Feed Instagram}


Dibuatnya desain feed Instagram agar dapat menarik calon pelanggan, menjalin hubungan baik atau kerjasama dengan instansi serta dapat digunakan sebagai media informasi untuk meningkatkan citra PT. Timoti agar lebih terkenal dengan produknya khususnya Tangerang dan sekitarnya. Dengan menggunakan media promosi berupa Instagram feeds maka PT. Timoti Beauty akan lebih modern dalam menyampaikan informasi dan mempromosikan produk yang ditawarkannya.

\subsection{Layout Kasar}

Layout kasar adalah gambar kerja yang menunjukkan tata letak naskah dan komposisi gambar yang akan dibuat. Biasanya pada layout kasar ini dibuat hitam putih menggunakan coretan-coretan tangan atau sketsa pensil.

berikut adalah proses desain layout kasar yang dibuat:

- Insta Feed 9.9 Flash Sale dan Insta Feed Q\&A Skincare Tips, Life style, and Fashion
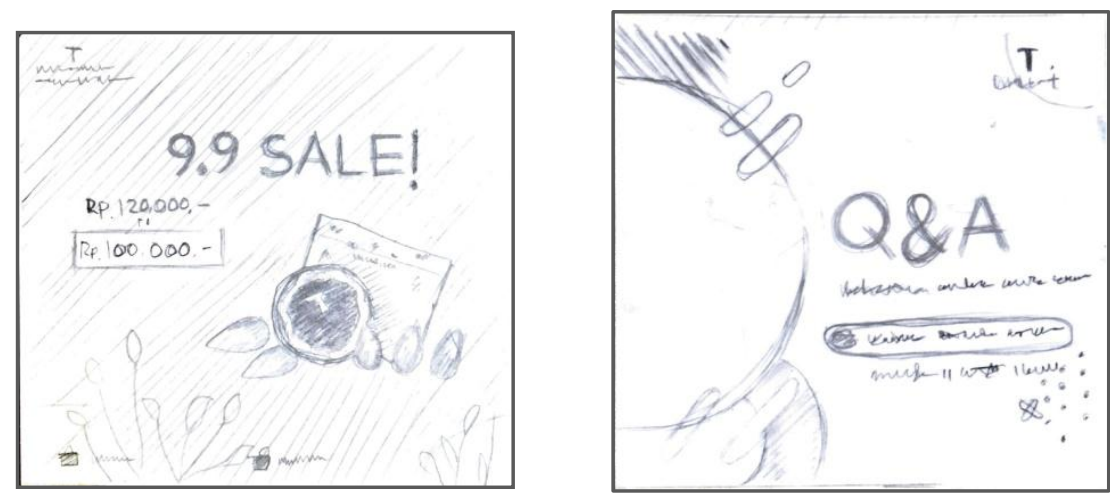

Gambar 1 dan 2. Layout kasar pada Insta Feed 9.9 Flash Sale dan Insta Feed Q\&A Skincare Tips, Life style, and Fashion

- Insta Feed "Live Beauty: Teknik Mengaplikasikan Eyeshadow agar terlihat Cerah" dan Insta Feed "Selamat Hari Palang Merah Indonesia ke-75"
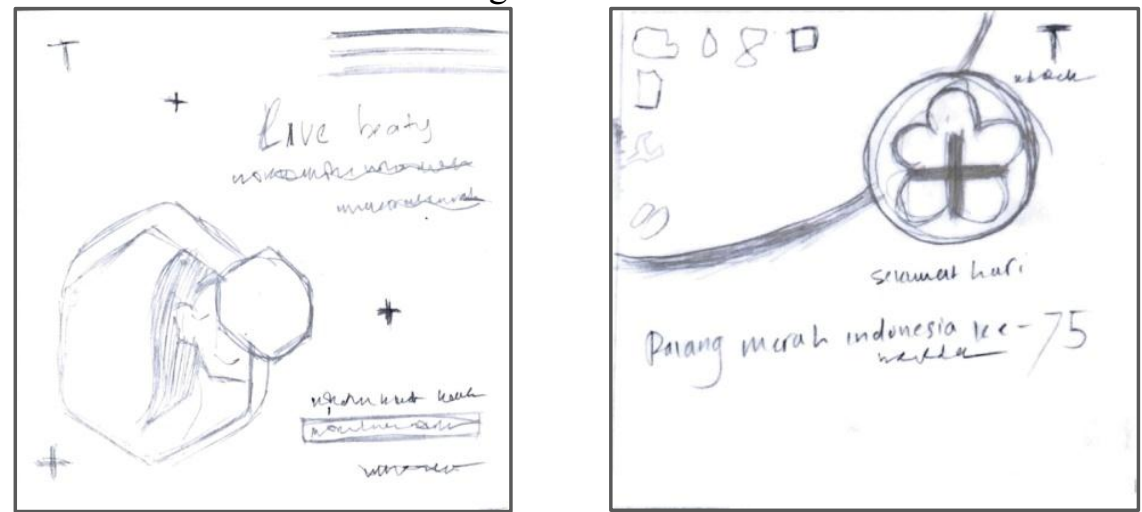

Gambar 3 dan 4. Layout kasar pada Insta Feed "Live Beauty: Teknik Mengaplikasikan Eyeshadow agar terlihat Cerah" dan Insta Feed "Selamat Hari Palang Merah Indonesia ke-75" 
- Insta Feed "The Great Moment of Makeup Puff" dan Insta Feed "International Day of Peace"
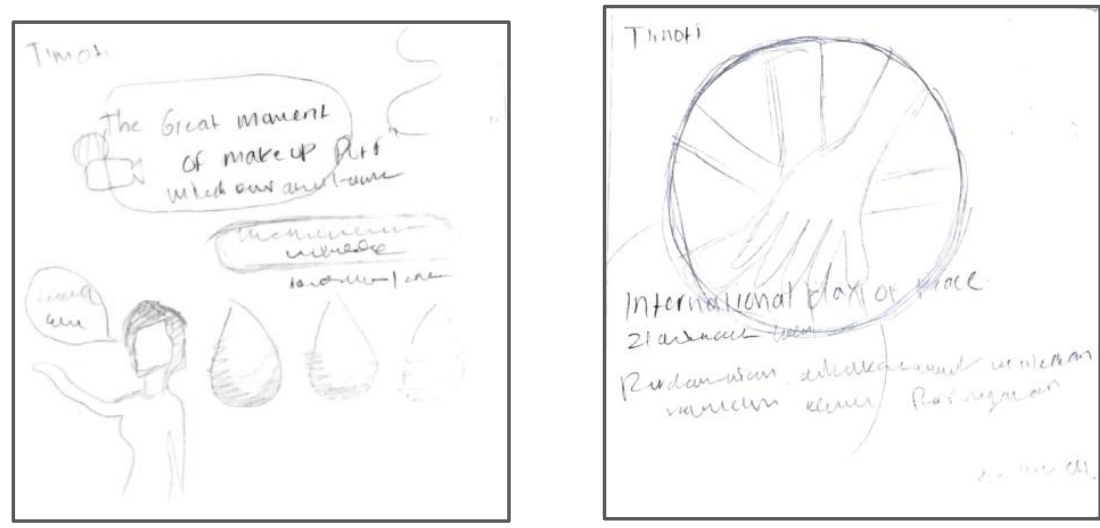

Gambar 5 dan 6. Layout kasar pada Insta Feed "The Great Moment of Makeup Puff" dan Insta Feed "International Day of Peace"

- Insta Feed "Live Beauty: Eyeliner tips for Asian Makeup" dan Insta Feed "The Great Moment of Makeup Puff 2"
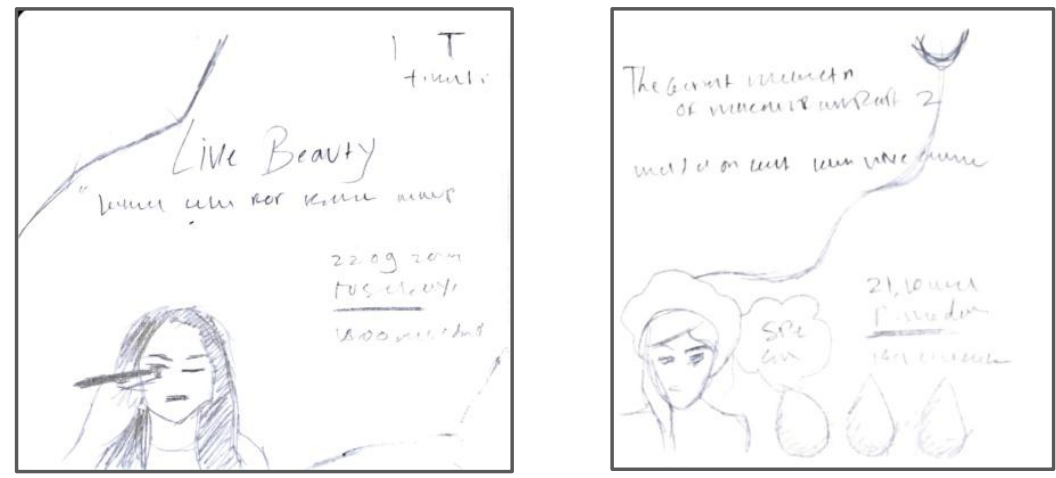

Gambar 7 dan 8. Layout kasar pada Insta Feed "Live Beauty: Eyeliner tips for Asian Makeup" dan Insta Feed "The Great Moment of Makeup Puff 2"

- Insta Feed Promo Hari Guru Sedunia
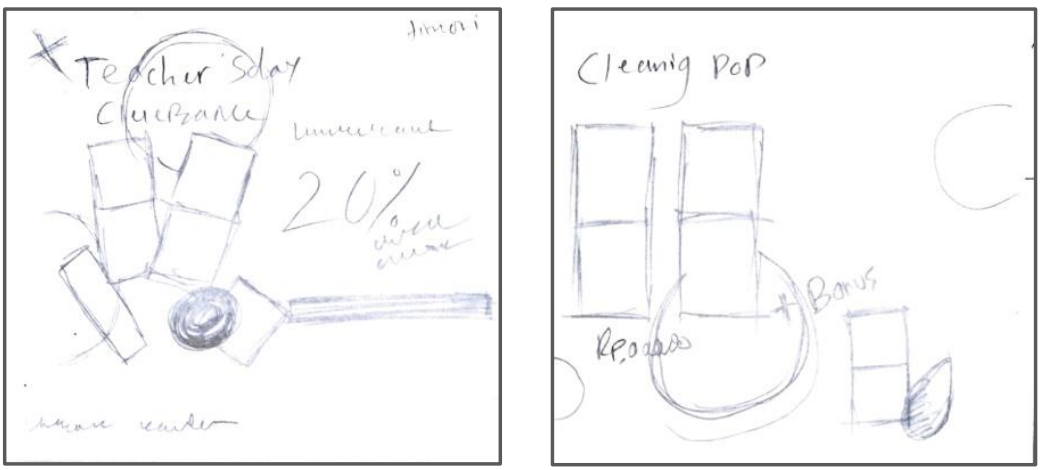

Gambar 9 dan 10. Layout kasar pada Insta Feed Promo Hari Guru Sedunia 

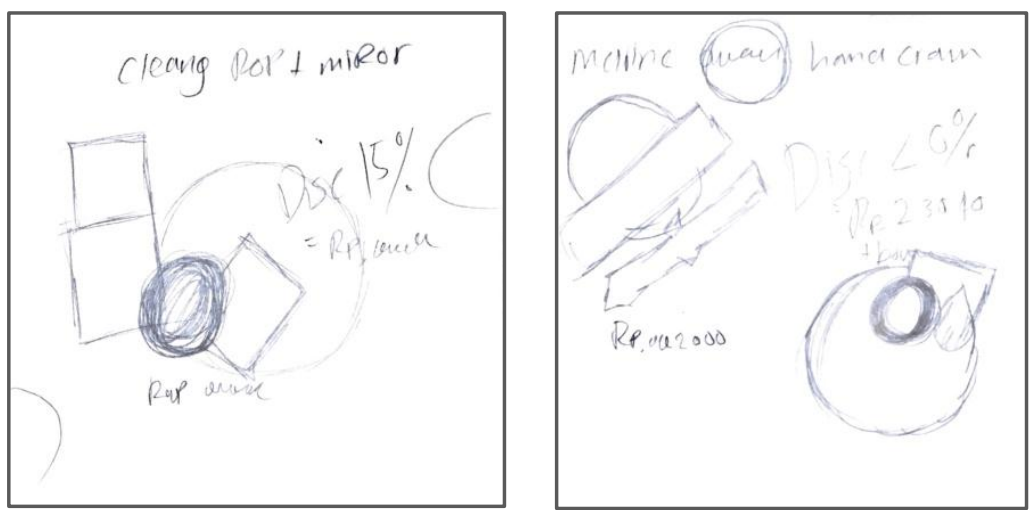

Gambar 11 dan 12. Layout kasar pada Insta Feed Promo Hari Guru Sedunia

\subsection{Layout Komprehensif}

Layout komprehensif adalah gambar yang mendekati komposisi akhir, dalam hal ini sudah mulai memasuki tahap komputerisasi kemudian komposisi gambar biasanya disajikan dalam warna dan diwarnai oleh perangkat lunak CorelDraw dan Photoshop. Berikut adalah proses Layout Komprehensif pada desain feed Instagram dalam tahap desain:
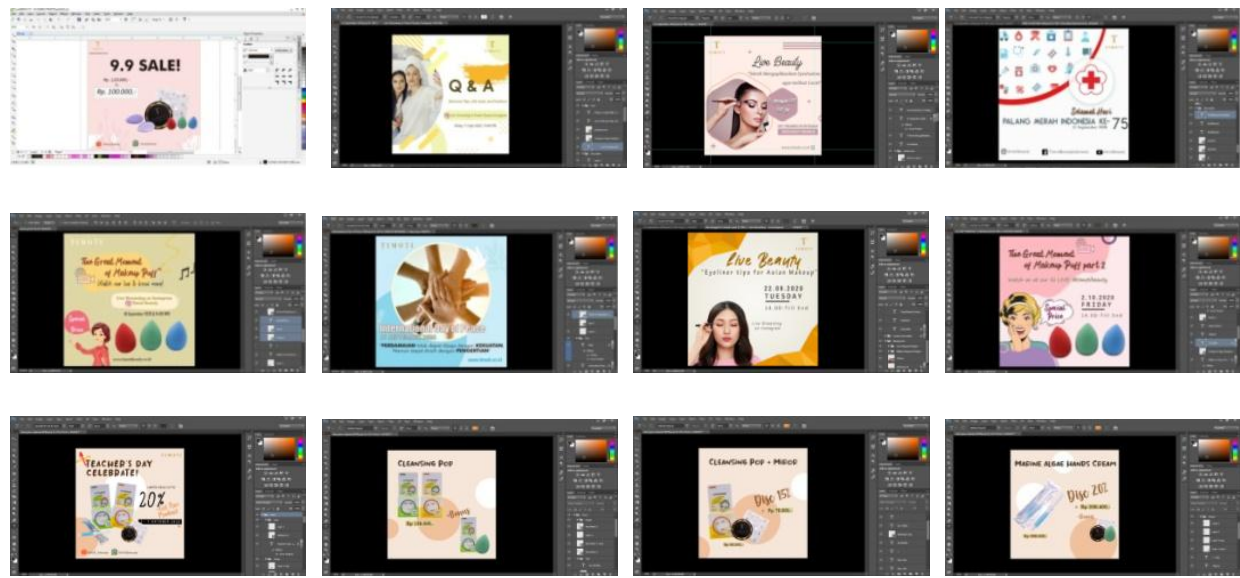

Gambar 13. Layout Komprehensif Feed Instagram

\subsection{Final Artwork}

Final Artwork merupakan gambar pekerjaan akhir yang telah diulas beberapa kali. Proses sebelumnya adalah layout kasar yang komprehensif. Selama proses ini, skrip tata letak gambar adalah proses akhir persiapan yang dihasilkan oleh proses tersebut Setelah pencetakan atau jenis media elektronik lainnya disempurnakan.

Berikut hasil pengerjaan final artwork pada feed instagram Timoti Beauty kemudian gambar dengan ukuran 1:1. 
- Insta Feed 9.9 Flash Sale dan Insta Feed Q\&A Skincare Tips, Life style, and Fashion
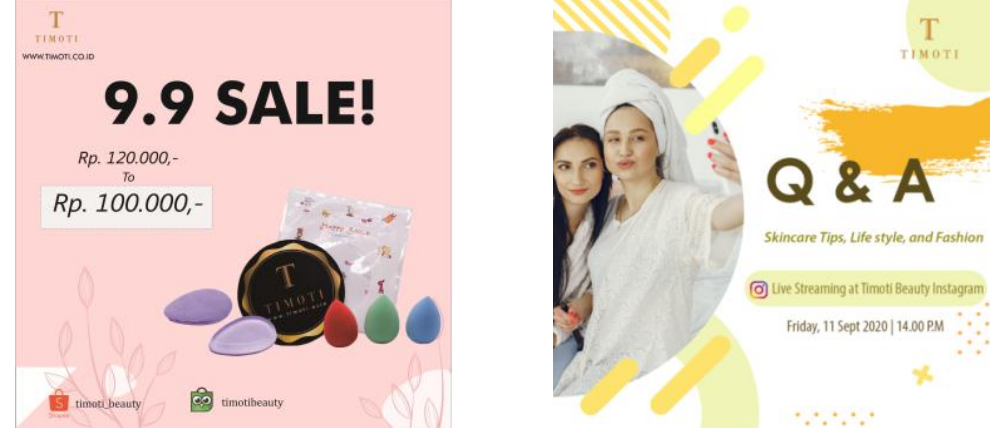

Gambar 14 dan 15. Final Artwork Insta Feed 9.9 Flash Sale dan Insta Feed Q\&A Skincare Tips, Life style, and Fashion

- Insta Feed "Live Beauty: Teknik Mengaplikasikan Eyeshadow agar terlihat Cerah" dan Insta Feed "Selamat Hari Palang Merah Indonesia ke-75"
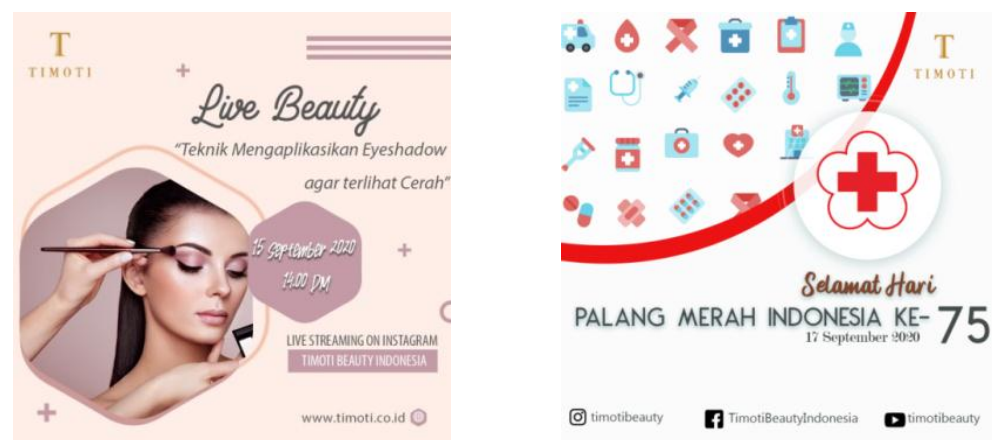

Gambar 16 dan 17. Final Artwork Insta Feed "Live Beauty: Teknik Mengaplikasikan Eyeshadow agar terlihat Cerah" dan Insta Feed "Selamat Hari Palang Merah Indonesia ke-75"

- Insta Feed "The Great Moment of Makeup Puff" dan Insta Feed "International Day of Peace"
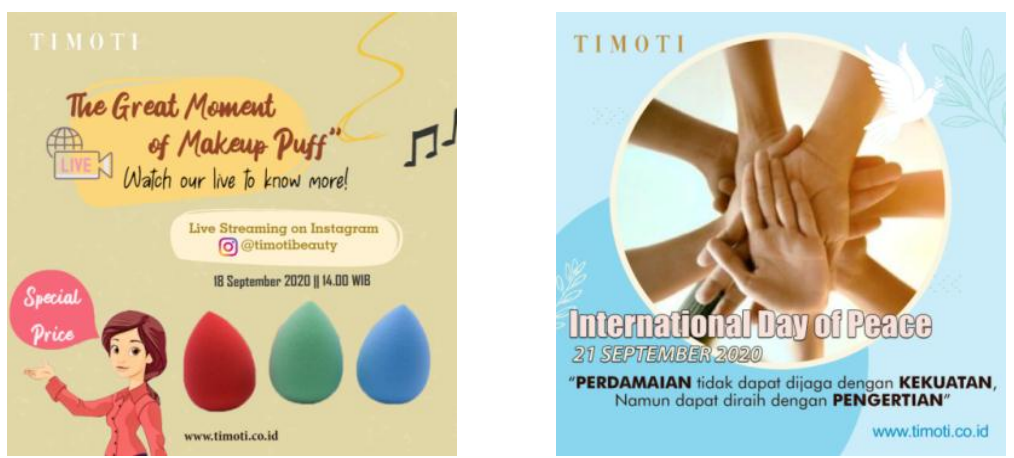

Gambar 18 dan 19. Final Artwork Insta Feed "The Great Moment of Makeup Puff" dan Insta Feed "International Day of Peace" 
- Insta Feed "Live Beauty: Eyeliner tips for Asian Makeup" dan Insta Feed "The Great Moment of Makeup Puff 2".
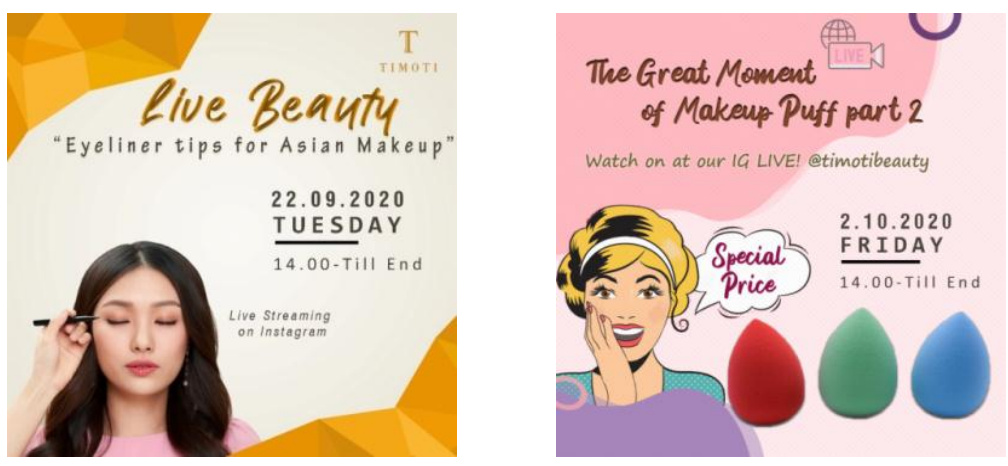

Gambar 20 dan 21. Final Artwork Insta Feed "Live Beauty: Eyeliner tips for Asian Makeup" dan Insta Feed "The Great Moment of Makeup Puff 2"

- Insta Feed Promo Hari Guru Sedunia
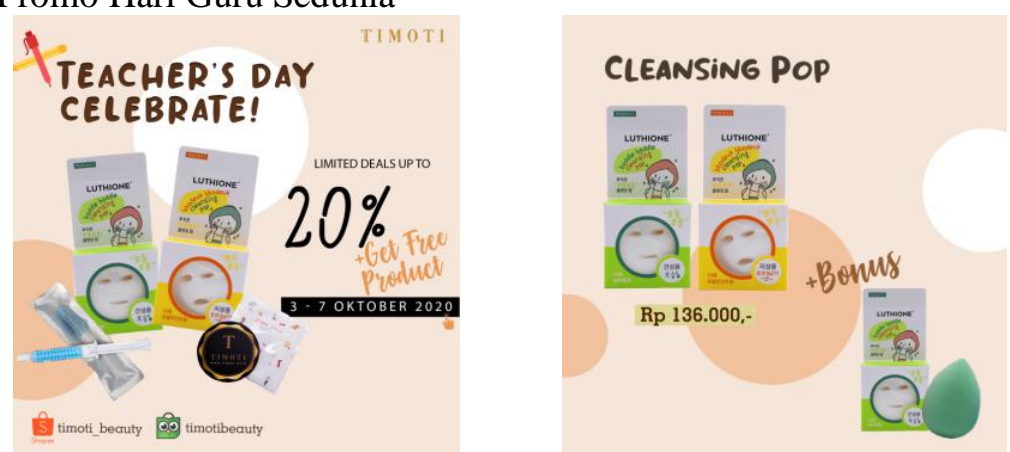

Gambar 22 dan 23. Final Artwork Insta Feed Promo Hari Guru Sedunia
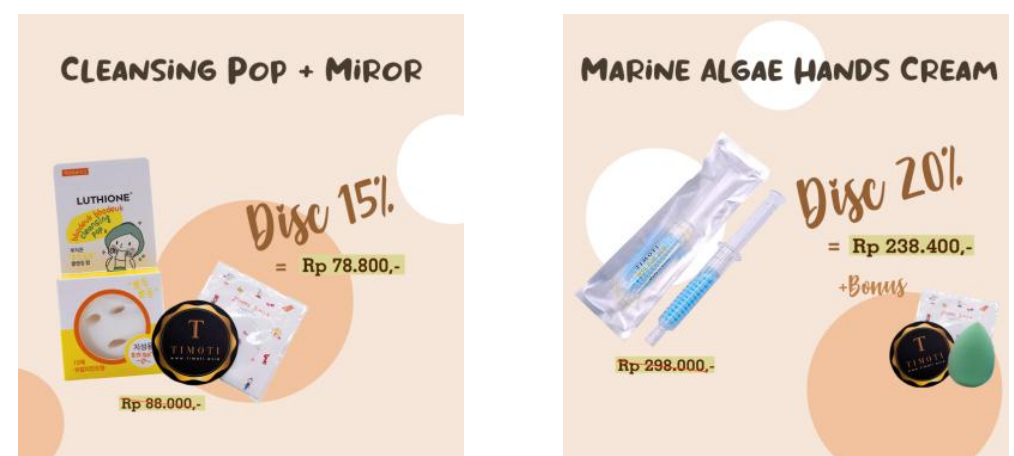

Gambar 24 dan 25. Final Artwork Insta Feed Promo Hari Guru Sedunia

\section{KESIMPULAN}

Instagram merupakan aplikasi media sosial yang menempati urutan ketiga di antara sebagian besar pengguna aplikasi di dunia. Oleh karena itu, perlu dibuat akun bisnis baru di media sosial Instagram. Desain media dari feed Instagram yang dirancang mewujudkan elemen yang efektif dan efisien, dapat memberikan informasi promosi, dan menggunakan desain yang unik untuk dikemas dalam masyarakat saat ini dengan cara yang menarik dan modern. Tujuan yang ingin dicapai PT. Timoti Beauty Indonesia setelah menerapkan media desain feed 
Instagram diharapkan dapat meningkatkan kepercayaan konsumen dan mempromosikan produk yang disediakannya secara modern.

\section{SARAN}

Dalam proses mendesain desain feed Instagram yang menarik, diperlukan pemahaman yang lebih baik tentang desain dan fenomena sosial. Hal ini ditujukan agar rancangan desain yang ada jauh lebih sesuai dengan keadaan yang sedang terjadi. Dalam proses pengerjaannya juga sangat perlu dipahami prinsip-prinsip desain agar tercipta karya desain yang lebih ideal. Untuk kedepannya, sebuah desain dan gaya desain pasti akan mengalami perubahan. Maka dari itu dengan mencari banyak-banyak referensi desain juga akan menambah wawasan luas tentang desain. Software yang digunakan dalam membuat sebuah desain feed Instagram ini adalah Adobe Photoshop dan Corel Draw, namun perlu ada sebuah inovasi-inovasi baru yang harus dicoba dalam merencang sebuah desain. Dan yang paling baik adalah mampu mengkombinasikan antara Software satu dengan Software lainnya, sehingga rancangan desain yang dihasilkan juga pasti akan menjadi inovasi desain baru.

Semoga lebih banyak lagi rancangan-rancangan desain feed intagram yang unik dan menarik, yang menandakan perkembangan desainer Indonesia lebih maju.

\section{DAFTAR PUSTAKA}

[1] Zebua, Manahati. 2016. Pemasaran Pariwisata : Menuju Festival Sail. Yogyakarta: Deepublish. ISBN 978-602-401-129-1

[2] Ubaidah, Nur Ahmad. 2017. Strategi Pemasaran Yang Efektif Untuk Perkembangan Usaha Anda. Diambil dari: https://www.logique.co.id/blog/2017/09/27/strategi-pemasaranefektif-bagi-usaha/. (27 September 2017)

[3] Sis, Atika Robiatun A dan Albari. 2015. Pengukuran Efektifitas Pengiklanan Lingkungan Melalui Iklan Televisi (Pendekatan Model Aida). Yogyakarta: Universitas Islam Indonesia. KINERJA: Volume 19, No.1, Th. 2015: Hal. 16-26.

[4] Wolah, Ferni Fera Ch. 2016. Peranan Promosi Dalam Meningkatkan Kunjungan Wisatawan Di Kabupaten Pos. e- journal Acta Diurna: Vol.5, No.2. ISSN: 26856999

[5] Februri, Muhammad R. Adam Idris dan Anwar Alaydrus. 2018. Pengaruh Media Elektronik Terhadap Tingkat Partisipasi Politik Masyarakat Kecamatan Sungai Pinang Pada Pilkada Kota Samarinda Tahun 2015. Samarinda: E-Journal Ilmu Pemerintahan: Vol.6, No.3. 1159-1168. ISSN: 2477-2458 (online), ISSN: 24772631 (cetak).

[6] Sari, Astari Clara. Rini Hartina, Reski Awalia, dkk. 2018. Komunikasi Dan Media Sosial. Makassar: Universitas Muslim Indonesia. Fakultas Sastra.

[7] Hernawati. 2016. Pengaruh Media Sosial Terhadap Perilaku Masyarakat. Diambil dari: https://sulselprov.go.id/welcome/post/pengaruh-media-sosial-terhadap-perilakumasyarakat. (16 November 2016).

[8] Putri, Almida Elit. 2019. Strategi Promosi Melalui Media Sosial Dalam Pengembangan Produk-Produk Bank Syariah (Studi Pada Bni Syariah Cabang Bengkulu). Bengkulu: Institut Agama Islam Negeri Bengkulu.

[9] Maimunah, Maimunah. Lusyani Sunarya, Ferry, dkk. 2015. Enriching Merchandise sebagai Salah Satu Media Promosi Mal Taman Palem. Jurnal Semnasteknomedia Vol 3, No 1

[10] Sunarya, Lusyani. dan Jasmine Dara. 2015. Keefektifan Media Komunikasi Visual Sebagai Penunjang Promosi Pada Perguruan Tinggi Raharja. Tangerang: Perguruan Tinggi Raharja. ISSN: 1978-8282. Journal CCIT Vol. 9 No. 1

[11] Andriyanti, Riska. 2016. Perancangan Majalah Sebagai Penunjang Informasi Dan Promosi Pada TK Putra IX Tangerang. Tangerang: STMIK Raharja.

21 
Print ISSN: 2723-1992

Online ISSN: 2723-200X

[12] Sunarya, Lusyani, dkk. 2017. Desain Komunikasi Visual Sebagai Media Promosi Pada SMK Al-Hikmah Curug Kabupaten Tangerang. Tangerang: Perguruan Tinggi Raharja. Jurnal SISITI Vol.5 No.1 : 611.

[13] Diyatma, Aris Jatmika. 2017. Pengaruh Promosi Melalui Media Sosial Instagram Terhadap Keputusan Pembelian Produk Saka Bistro \& Bar. Bandung: Universitas Telkom. e-Proceeding of Management : Vol.4, No.1. ISSN : 2355-9357. 